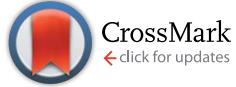

Cite this: J. Mater. Chem. A, 2017, 5, 4156

Received 19th September 2016 Accepted 16th January 2017

DOI: $10.1039 / c 6 t a 08106 a$

www.rsc.org/MaterialsA

\section{A fullerene alloy based photovoltaic blend with a glass transition temperature above $200{ }^{\circ} \mathrm{C} \uparrow$}

\author{
Amaia Diaz de Zerio Mendaza, ${ }^{a}$ Armantas Melianas, ${ }^{b}$ Ferry A. A. Nugroho, ${ }^{c}$ \\ Olof Bäcke, ${ }^{c}$ Eva Olsson, ${ }^{c}$ Christoph Langhammer, ${ }^{c}$ Olle Inganäs ${ }^{b}$ \\ and Christian Müller ${ }^{\star a}$
}

\begin{abstract}
Organic solar cells with a high degree of thermal stability require bulk-heterojunction blends that feature a high glass transition, which must occur considerably above the temperatures encountered during device fabrication and operation. Here, we demonstrate for the first time a polymer : fullerene blend with a glass transition temperature above $200^{\circ} \mathrm{C}$, which we determine by plasmonic nanospectroscopy. We achieve this strong tendency for glass formation through the use of an alloy of neat, unsubstituted $\mathrm{C}_{60}$ and $\mathrm{C}_{70}$, which we combine with the fluorothieno-benzodithiophene copolymer PTB7. A stable photovoltaic performance of PTB7 : $\mathrm{C}_{60}: \mathrm{C}_{70}$ ternary blends is preserved despite annealing the active layer at up to $180{ }^{\circ} \mathrm{C}$, which coincides with the onset of the glass transition. Rapid deterioration of the power conversion efficiency from initially above $5 \%$ only occurs upon exceeding the glass transition temperature of $224^{\circ} \mathrm{C}$ of the ternary blend.
\end{abstract}

\section{Introduction}

Organic photovoltaics receives tremendous interest as an alternative solar cell technology because of its compatibility with low-cost manufacturing through roll-to-roll coating and printing techniques. The active layer material is typically designed according to the bulk-heterojunction concept, i.e. an intimate blend of an electron donor and an acceptor. The most widely explored type of acceptor is fullerenes, which together with polymeric donors can give rise to power conversion efficiencies above $11 \%$ in the case of lab-scale devices ${ }^{1}$ and $7.5 \%$ in the case of small modules. ${ }^{2}$

One important requirement for both high-throughput manufacturing and long-term use of polymer : fullerene bulkheterojunctions is excellent thermal stability. The material must be able to withstand elevated processing temperatures because the coating speed is limited by the rate of solvent removal, which can be accelerated by heating. The choice of substrate determines the highest possible processing temperature, e.g. $140^{\circ} \mathrm{C}$ in the case of poly(ethylene terephthalate) (PET) foil. ${ }^{3,4}$ Moreover, during operation the solar cell must be able to handle temperatures up to $85{ }^{\circ} \mathrm{C}$, as required by industry standards. ${ }^{5}$

\footnotetext{
${ }^{a}$ Department of Chemistry and Chemical Engineering, Chalmers University of Technology, 41296 Göteborg, Sweden. E-mail: christian.muller@chalmers.se

${ }^{b}$ Biomolecular and Organic Electronics, IFM, Linköping University, 58183 Linköping, Sweden

'Department of Physics, Chalmers University of Technology, 41296 Göteborg, Sweden $\dagger$ Electronic supplementary information (ESI) available. See DOI: 10.1039/c6ta08106a
}

For the majority of donor: acceptor blends, the optimal nanostructure, which leads to the highest photovoltaic performance, is located far away from thermal equilibrium. To prevent reorganisation of the nanostructure upon heating, it is necessary to select blends that are characterised by a high glass transition temperature $T_{\mathrm{g}}{ }^{6}$ This concept was first proposed by Yang et al. and Bertho et al. and is now an accepted design criterion for thermally stable organic solar cells. ${ }^{7-9}$ A finely mixed blend typically displays a single $T_{\mathrm{g}}$ and its nanostructure remains frozen in, as long as the blend remains far below this critical temperature. As such the glass transition should be considered as a kinetic phenomenon that represents a nominal temperature below which relaxation of the donor polymer and diffusion of the fullerene acceptor are strongly slowed down but not prevented. ${ }^{6}$

Rapid solidification from solution can lead to nanostructures where a relatively large amount of free volume is trapped below $T_{\mathrm{g}}$ (cf. ref. 10: the thickness of a spin-coated fluorenebenzothiadiazole copolymer thin film decreases by more than one percent when heated above $T_{\mathrm{g}}$ ). Heating below but sufficiently close to $T_{\mathrm{g}}$, which can occur during the manufacture and operation of a solar cell, is likely to result in gradual rearrangement of donor and acceptor molecules. For instance, we have shown that such sub- $T_{\mathrm{g}}$ annealing can occur in blends based on the thiophene-quinoxaline copolymer TQ1, with local structural changes (inferred from photoluminescence and UV-vis spectroscopy) taking place as much as $70{ }^{\circ} \mathrm{C}$ below the nominal $T_{\mathrm{g}} \sim$ $110{ }^{\circ} \mathrm{C} .{ }^{11}$ Thus, it would be desirable to identify donor : acceptor blends that feature a $T_{\mathrm{g}}$, which lies significantly above the maximum processing temperature, e.g. $140{ }^{\circ} \mathrm{C}$ for PET foil. 
Substituted fullerenes such as $\mathrm{PC}_{61} \mathrm{BM}$ and $\mathrm{PC}_{71} \mathrm{BM}$, which are most commonly used, feature a $T_{\mathrm{g}}$ of about $110-130{ }^{\circ} \mathrm{C}$ (ref. 10, 12 and 13) and $160{ }^{\circ} \mathrm{C},{ }^{\mathbf{1 4 1 1 5}}$ respectively. When mixed with common donor polymers, blends with a glass transition of typically around $100{ }^{\circ} \mathrm{C}$ are obtained, ${ }^{6}$ which may not be sufficiently high to ensure complete thermal stability during processing. One approach to further enhance the thermal stability around or above the $T_{\mathrm{g}}$ of the blend is the use of fullerene alloys, i.e. mixtures of several fullerene acceptors, which (depending on the choice of fullerenes) can either nucleate ${ }^{\mathbf{1 6 , 1 7}}$ or hinder fullerene crystal growth. ${ }^{18-22}$ Other advantages of fullerene alloys are cost-reduction and beneficial mechanical properties. ${ }^{23}$ Angmo et al. have shown that such alloys are fully compatible with slot-die coating and may enhance the solar cell efficiency. ${ }^{24}$ Recently, solar cells based on a $\mathrm{PC}_{61} \mathrm{BM}: \mathrm{PC}_{71} \mathrm{BM}$ alloy with an efficiency above $10 \%$ and good thermal stability at $130{ }^{\circ} \mathrm{C}$ have been demonstrated. ${ }^{20}$

We have recently explored the use of neat fullerene mixtures comprising $\mathrm{C}_{60}$ and $\mathrm{C}_{70}$ in ternary blends with either TQ1 or the fluorothieno-benzodithiophene copolymer PTB7 (Fig. 1), ${ }^{25,26}$ which promises a considerable reduction in the energy footprint of the acceptor material. ${ }^{27}$ In particular, we found that the $\mathrm{C}_{60}: \mathrm{C}_{70}$ mixture displays a significantly enhanced solubility in a wide range of organic solvents, which enabled the preparation of highly reproducible field-effect transistors with mobilities of $1 \mathrm{~cm}^{2} \mathrm{~V}^{-1}$ $\mathrm{s}^{-1}$ and solar cells with a power conversion efficiency of $6 \%{ }^{26}$ Moreover, the photovoltaic performance of the PTB7 : $\mathrm{C}_{60}: \mathrm{C}_{70}$ ternary blend was unaffected by annealing at $100{ }^{\circ} \mathrm{C}$, which suggests that the use of $\mathrm{C}_{60}: \mathrm{C}_{70}$ alloys gives rise to a high glass transition temperature. We rationalized the enhanced solubility of $\mathrm{C}_{60}: \mathrm{C}_{70}$ mixtures and their tendency for glass formation by the increase in configurational entropy upon mixing. ${ }^{26}$

Here, we study the photovoltaic performance of ternary PTB7 : $\mathrm{C}_{60}: \mathrm{C}_{70}$ blends exposed to extreme annealing temperatures up to $300{ }^{\circ} \mathrm{C}$. To detect the glass transition temperature we employ plasmonic nanospectroscopy, ${ }^{28,29}$ a technique based on localised surface plasmon resonance (LSPR), which is particularly sensitive in detecting phase transitions in organic thin films. We have recently shown that this method is valid for
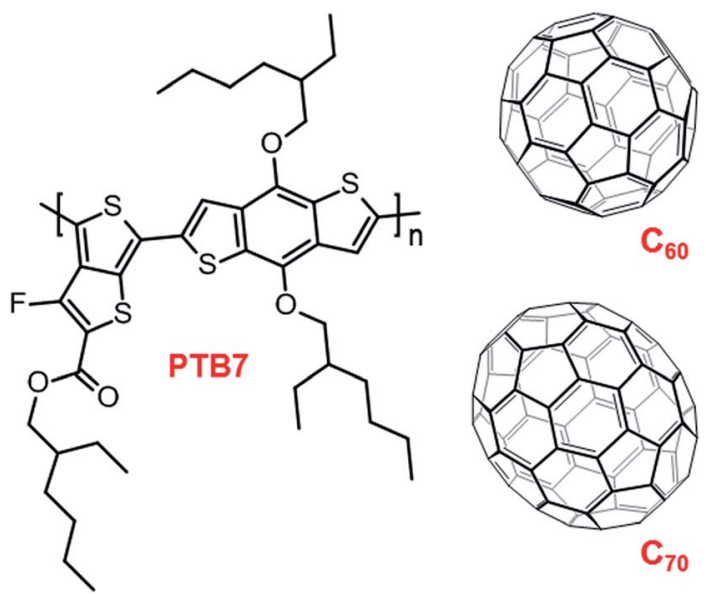

Fig. 1 Chemical structure of PTB7, $\mathrm{C}_{60}$ and $\mathrm{C}_{70}$. organic photovoltaic blends. ${ }^{30}$ We find that photovoltaic devices based on PTB7 : $\mathrm{C}_{60}: \mathrm{C}_{70}$ display excellent thermal stability with a glass transition temperature at $T_{\mathrm{g}} \sim 224{ }^{\circ} \mathrm{C}$ and a thermally stable photovoltaic performance up to $\sim 180^{\circ} \mathrm{C}$.

\section{Results and discussion}

In a first set of experiments we employed plasmonic nanospectroscopy to determine the glass transition temperature of the here investigated PTB7 $: \mathrm{C}_{60}: \mathrm{C}_{70}$ ternary blend with a $2: 1: 1$ stoichiometry. This technique exploits LSPR, i.e. photon-driven electron oscillation in metallic nanoparticles positioned on a planar surface, which gives rise to locally enhanced electric fields that are highly sensitive to changes in the surrounding medium. ${ }^{31}$ Embedding the nanoparticles in an organic thin film permits us to monitor minute changes in refractive index upon heating due to expansion, which results in a shift in the peak wavelength $\lambda_{\text {peak }}$ of the plasmonic resonance by $\Delta \lambda_{\text {peak }}=\lambda_{\text {peak }}(T)$ $-\lambda_{\text {peak }}(\mathrm{RT})$. Any phase transition is accompanied by an abrupt change in the linear expansion coefficient, and thus manifests itself as a change in the rate by which $\Delta \lambda_{\text {peak }}$ varies with temperature, i.e. $\mathrm{d}\left(\Delta \lambda_{\text {peak }}\right) / \mathrm{d} T$ ( $c f$. ref. 30 for details).

We deposited PTB7 : $\mathrm{C}_{60}: \mathrm{C}_{70}$ thin films with a thickness of about $100 \mathrm{~nm}$ on a suitable plasmonic sensor chip (see Experimental). As active nanoantennas in our sensor, we chose $\mathrm{Au}$ nanodisks with a diameter of $170 \mathrm{~nm}$ and height of $20 \mathrm{~nm}$, which give rise to a plasmonic resonance at $\lambda_{\text {peak }} \sim 920 \mathrm{~nm}$. As a result, we were able to avoid overlap with the absorption band of the ternary blend (Fig. 2a). During the first heating scan from 60 to $250{ }^{\circ} \mathrm{C}$ we observe a continuous blue shift of $\Delta \lambda_{\text {peak }}$ with a clear change in slope $\mathrm{d}\left(\Delta \lambda_{\text {peak }}\right) / \mathrm{d} T$ around $224 \pm 1^{\circ} \mathrm{C}$, which we identify as the glass transition temperature of the ternary blend (Fig. 2b). We note that $\mathrm{d}\left(\Delta \lambda_{\text {peak }}\right) / \mathrm{d} T$ starts to change before this nominal $T_{\mathrm{g}}$ $\sim 224{ }^{\circ} \mathrm{C}$ is reached (with an onset around $180{ }^{\circ} \mathrm{C}$, see ESI, Fig. $\mathrm{S} 1 \dagger$ ), which indicates that structural changes can occur at considerably lower temperatures. We also carried out plasmonic nanospectroscopy on neat PTB7 but did not observe any change in $\mathrm{d}\left(\Delta \lambda_{\text {peak }}\right) / \mathrm{d} T$ (ESI, Fig. S2 $\dagger$ ). Differential scanning calorimetry (DSC) of neat PTB7 reveals a shallow exotherm between 140 and $210{ }^{\circ} \mathrm{C}$ in second heating thermograms, which persists in the ternary blend (ESI, Fig. S3†). We conclude that the polymer is able to undergo structural reorganisation in this temperature range, which suggests that its glass transition temperature may be found below $140{ }^{\circ} \mathrm{C}$.

The plasmonic signal recorded during subsequent heating scans differs from the first heating scan. We observe a smaller change in $\Delta \lambda_{\text {peak }}$ and a linear region that persists up to above $200{ }^{\circ} \mathrm{C}$ (ESI, Fig. S4 $\dagger$ ), which suggests a higher onset of the glass transition temperature as compared to the first heating scan. We attribute this behaviour to the irreversible crystallisation that occurs when the ternary blend is heated above its $T_{\mathrm{g}}$, as investigated in detail below. Moreover, thermogravimetric analysis (TGA) indicates a weight loss of about $2 \%$ for PTB7 : $\mathrm{C}_{60}: \mathrm{C}_{70}$ between 80 and $160{ }^{\circ} \mathrm{C}$ (ESI, Fig. S3†), which we associate with trapped solvent (note that we observe a similar weight loss for $\mathrm{C}_{60}: \mathrm{C}_{70}$ but none for PTB7). The tendency of fullerenes to trap chlorinated solvents is well documented and 
a
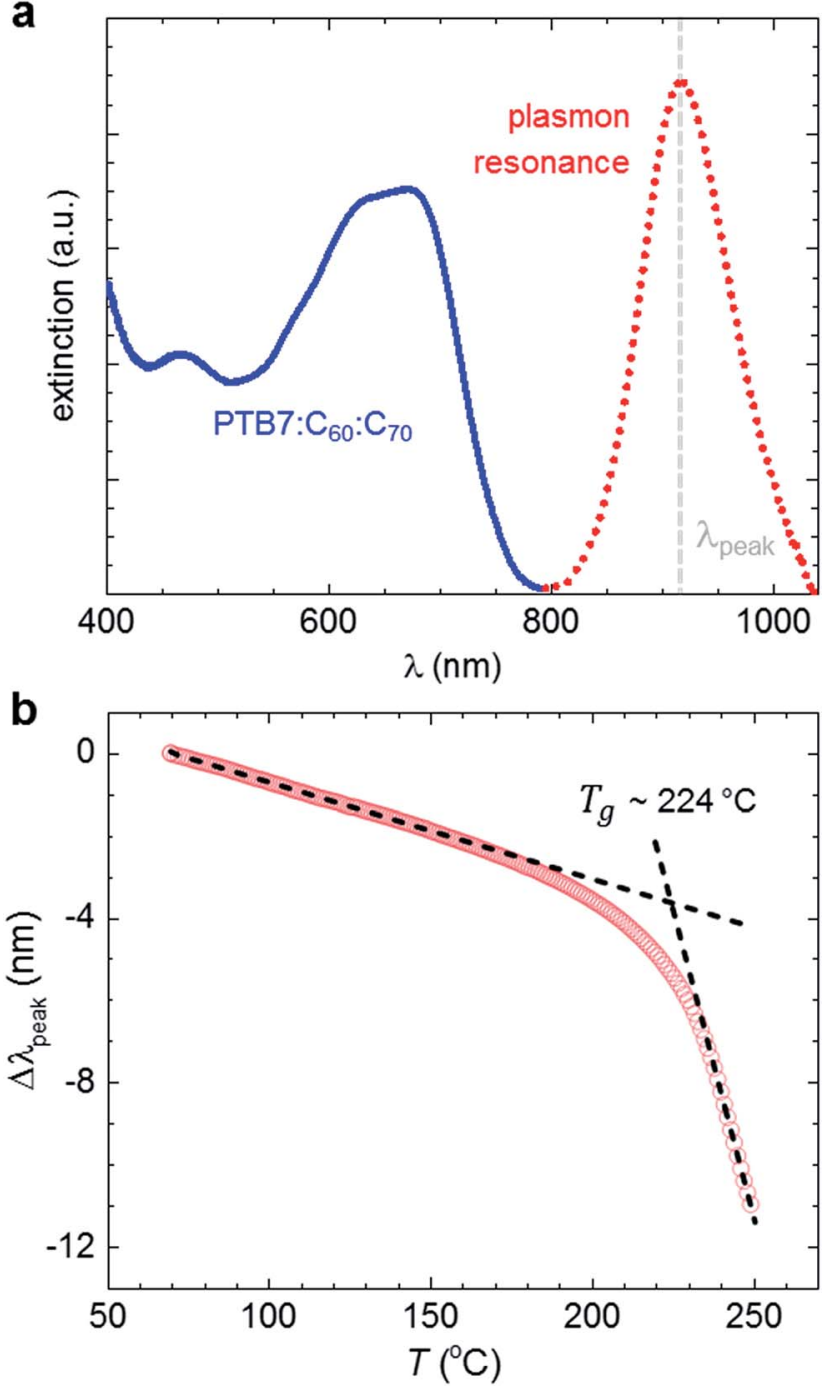

Fig. 2 (a) Optical extinction of a $2: 1: 1$ PTB7: $\mathrm{C}_{60}: \mathrm{C}_{70}$ thin film (blue) and the localised surface plasmon resonance (LSPR) of the embedded Au nanodisks (red). (b) Plasmonic nanospectroscopy: first heating scan to monitor the shift in the LSPR peak $\Delta \lambda_{\text {peak }}$ during heating from 60 to $250{ }^{\circ} \mathrm{C}$ (red); the intersection of the straight line fits (dashed) indicates a thermal transition, which we interpret as the glass transition temperature $T_{\mathrm{g}} \sim 224^{\circ} \mathrm{C}$.

may contribute to the observed lower $T_{\mathrm{g}}$ that we observe for the first heating scan.

A number of studies concerning other polymer : fullerene blends have established that coarsening and/or fullerene crystallisation tend to occur upon heating above $T_{\mathrm{g} \cdot}{ }^{6-9,32} \mathrm{We}$ used transmission electron microscopy (TEM) and selected area electron diffraction (SAED) to examine the nanostructure of spincoated $2: 1: 1$ PTB7 $: \mathrm{C}_{60}: \mathrm{C}_{70}$ thin films after annealing up to $240{ }^{\circ} \mathrm{C}$. In TEM bright field images no distinct, phase-separated domains can be resolved up to an annealing temperature $T_{\text {anneal }}$ $\sim 180{ }^{\circ} \mathrm{C}$. The corresponding SAED patterns only reveal an amorphous halo, which indicates that the initially fine nanostructure obtained through spin-coating is preserved (Fig. 3). Instead, annealing at $190{ }^{\circ} \mathrm{C}$ for $10 \mathrm{~min}$ resulted in the appearance of micrometre-sized single-crystal-like entities in TEM images, as well as sharp diffraction spots in the corresponding SAED patterns. These crystallites were surrounded by a featureless matrix (see ESI, Fig. S5† for atomic force microscopy). Annealing at higher temperatures resulted in an increase in both the density and size of crystals. For instance, $T_{\text {anneal }} \sim 240{ }^{\circ} \mathrm{C}$ gave rise to a dense coverage of 2 to $3 \mu \mathrm{m}$ large crystals that were surrounded
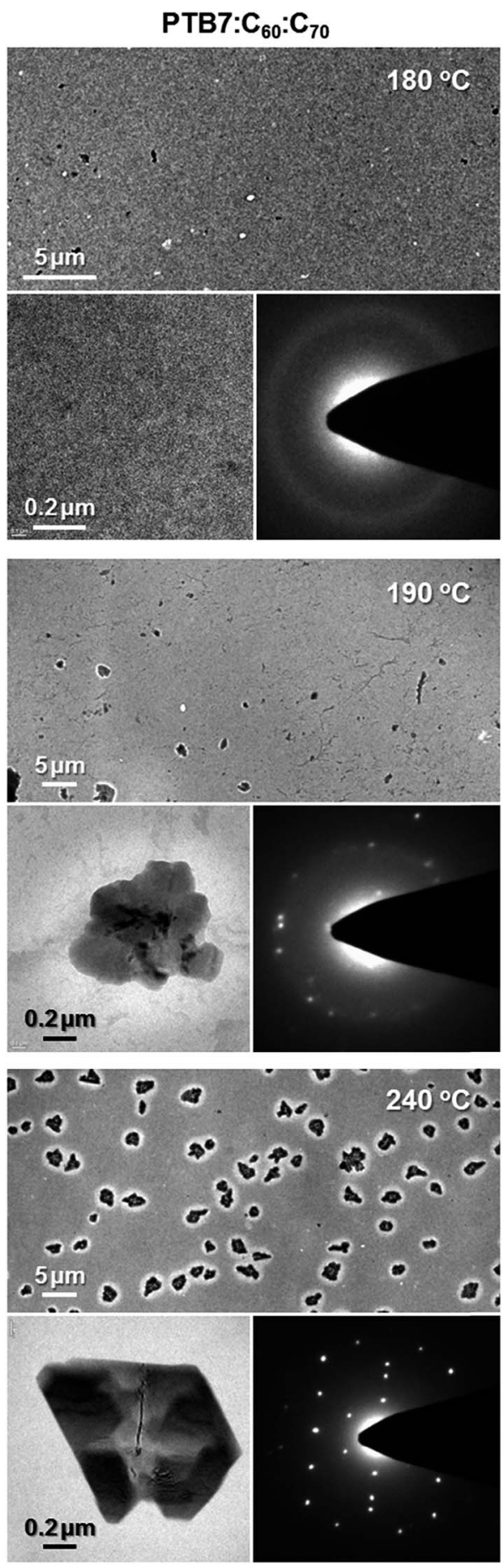

Fig. 3 TEM images at two magnifications and selected area electron diffraction patterns (bottom right) of $2: 1: 1$ PTB7 : $\mathrm{C}_{60}: \mathrm{C}_{70}$ thin films after annealing for $10 \mathrm{~min}$ at $180^{\circ} \mathrm{C}$ (top), $190^{\circ} \mathrm{C}$ (centre) and $240{ }^{\circ} \mathrm{C}$ (bottom). 
by a bright halo (Fig. 3). This depletion region is commonly observed around fullerene crystals that have grown in polymer: fullerene bulk-heterojunction blends, and arises because crystal growth has consumed the fullerene acceptor from the surrounding blend. ${ }^{7,8,32,33}$ The halo appears brighter than the surrounding film because of the higher electron density of fullerenes as compared to the remaining PTB7-rich material. We therefore conclude that the observed crystallites are composed of the fullerene material. SAED revealed distinct diffraction patterns, which confirm that the observed entities are single crystals.

To probe the impact of annealing on the local makeup of the ternary blend in more detail, we carried out photoluminescence (PL) spectroscopy. The PL emission of neat PTB7 is strongly quenched by a factor of 130 upon addition of the fullerene alloy (comparison of neat PTB7 and the as-cast ternary blend at room temperature). We observe no clear trend in PL quenching efficiency upon annealing the blend up to $T_{\text {anneal }} \sim 300{ }^{\circ} \mathrm{C}$ (ESI, Fig. S6†), which indicates that the conditions for exciton PL quenching and exciton dissociation are not significantly altered. We conclude that despite the removal of the fullerene material from part of the film ( $c f$. depletion regions in TEM images) a sufficiently large fraction of the acceptor remains present to effectively quench PL emission from neat PTB7.

In a further set of experiments we compared the thermal behaviour of the PTB7 : $\mathrm{C}_{60}: \mathrm{C}_{70}$ ternary blend with its photovoltaic performance. To this end we prepared solar cells with a ternary blend active layer that we annealed during device fabrication (see the inset in Fig. $4 \mathrm{~b}$ for device architecture). Active layers with a thickness of 100-110 nm were spin-coated onto the ITO/PEDOT : PSS anode, followed by annealing in a dark, nitrogen filled glovebox for $10 \mathrm{~min}$ at $T_{\text {anneal }}$ ranging from $\sim \mathrm{RT}$ to $300{ }^{\circ} \mathrm{C}$. The top $\mathrm{LiF} / \mathrm{Al}$ electrode was deposited after annealing. Devices were not encapsulated and measured in an ambient environment shortly after fabrication.

We find that for annealing at $T_{\text {anneal }} \leq 180{ }^{\circ} \mathrm{C}$ the photovoltaic performance is unaffected (Fig. 4). Averaging over all solar cells annealed at up to $180^{\circ} \mathrm{C}$ yields a short-circuit current density $J_{\mathrm{sc}} \sim 12.8 \pm 0.6 \mathrm{~mA} \mathrm{~cm}{ }^{-2}$, an open-circuit voltage $V_{\mathrm{oc}} \sim$ $0.67 \pm 0.01 \mathrm{~V}$, a fill factor $\mathrm{FF} \sim 0.62 \pm 0.02$ and a power conversion efficiency of PCE $\sim 5.3 \pm 0.3 \%$, with champion devices reaching $6 \%$. We note that the here observed thermal stability is in excellent agreement with the onset of the glass transition that we observed by plasmonic nanospectroscopy ( $c f$. Fig. 2b). At higher annealing temperatures both the $J_{\mathrm{sc}}$ and $\mathrm{FF}$ start to decrease, first only slightly for $180{ }^{\circ} \mathrm{C}<T_{\text {anneal }} \leq 220^{\circ} \mathrm{C}$, and then rapidly for $T_{\text {anneal }}>220{ }^{\circ} \mathrm{C}$. Evidently, the $T_{\mathrm{g}} \sim 224{ }^{\circ} \mathrm{C}$ of the ternary blend coincides with the annealing temperature at which a rapid loss in photovoltaic performance is observed.

Annealing at $260^{\circ} \mathrm{C}$ results in a near complete loss in $J_{\mathrm{sc}}$ from initially 12.8 to only $2 \mathrm{~mA} \mathrm{~cm}{ }^{-2}$. In contrast, no significant change in $V_{\mathrm{oc}}$ has occurred. PL and electroluminescence (EL) spectra of thin films annealed up to $T_{\text {anneal }} \sim 260{ }^{\circ} \mathrm{C}$ appear unchanged in shape and energetic position (ESI, Fig. S6 ${ }^{\dagger}$ ), which indicates that the energy of the charge-transfer state is unaffected by aggressive thermal treatment. The energy of the charge-transfer state is directly related to the generated photovoltage, ${ }^{34-36}$ which is in agreement with the observed invariance
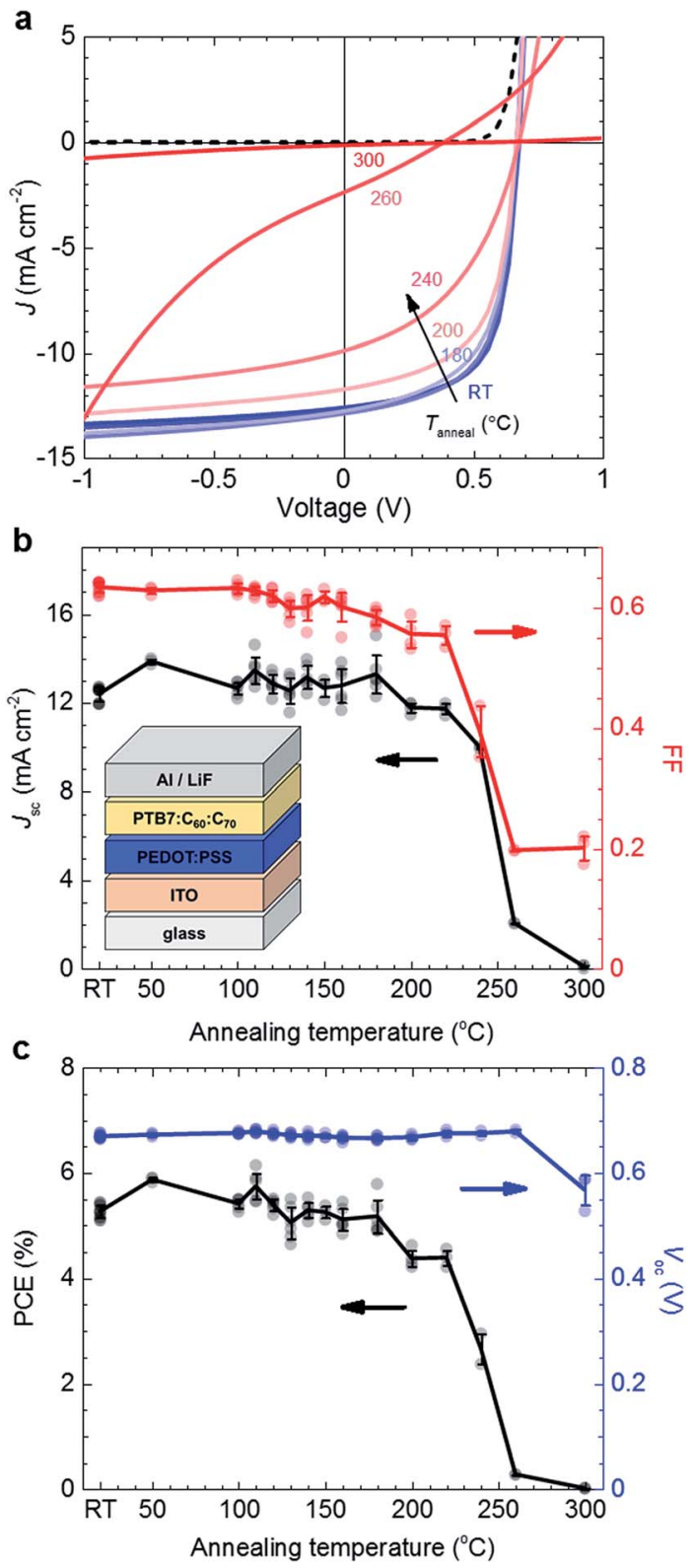

Fig. 4 (a) Representative current-voltage $J-V$ characteristics of $2: 1: 1$ PTB7 : $C_{60}: C_{70}$ devices comprising active layers that were thermally treated at $T_{\text {anneal, }}$ and dark current of an as-cast device (dashed). (b) $J_{\text {sc }}$ and FF, (c) MPP and $V_{\text {oc }}$ of $2: 1: 1$ PTB7 : $C_{60}: C_{70}$ devices as a function of $T_{\text {anneali }}$ each data point corresponds to a measured device, error bars indicate the standard deviation of 3-6 devices on the same substrate (solid lines are a guide to the eye); inset: solar cell device architecture. RT = room temperature.

in $V_{\text {oc }}$ (Fig. 4c). We conclude that the properties of the donor/ acceptor interface, which define the energetic position and the width of the EL emission, are unaffected upon annealing up to $260^{\circ} \mathrm{C}$. Since both EL and PL measurements indicate that the nanoscale phase separation is not significantly altered upon annealing, it is reasonable to assume that charge carrier transport through the bulk of the film is not affected. External quantum efficiency (EQE) spectra corroborate this picture. The shape of EQE spectra is comparable up to $T_{\text {anneal }} \sim 260{ }^{\circ} \mathrm{C}$ (Fig. 5), which suggests that the conditions for charge 


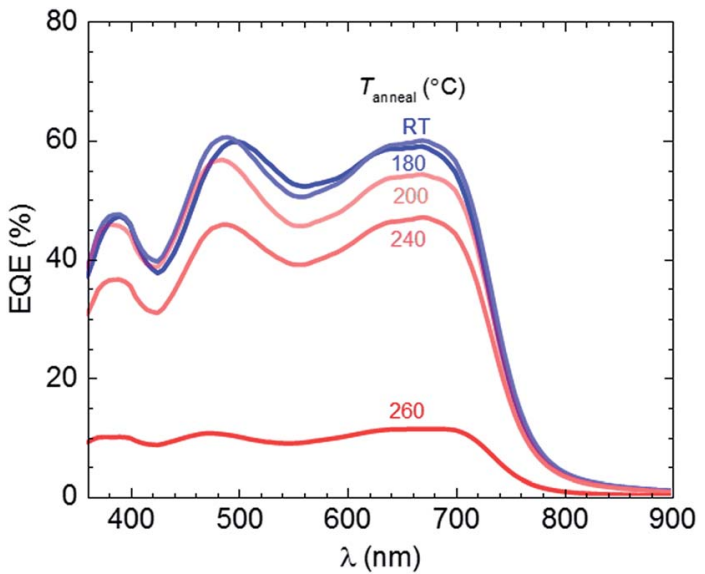

Fig. 5 External quantum-efficiency (EQE) spectra of $2: 1: 1$ PTB7 : $\mathrm{C}_{60}: \mathrm{C}_{70}$ devices after annealing at different temperatures from room temperature (RT) to $260{ }^{\circ} \mathrm{C}$ for $10 \mathrm{~min}$.

generation, related to the nanoscale phase separation of the photovoltaic blend, are not significantly affected upon thermal treatment. Instead, the decrease in device performance upon annealing at $T_{\text {anneal }}>180{ }^{\circ} \mathrm{C}$ likely arises due to a decrease in collection efficiency of photogenerated charges, which we tentatively assign to degradation of the interface of the active layer with the anode and/or cathode.

We carried out a final experiment to explore whether the here investigated use of neat fullerene mixtures is a general approach towards bulk heterojunction blends with a high glass transition temperature. We chose to study a ternary blend of $\mathrm{C}_{60}: \mathrm{C}_{70}$ and the thiophene-quinoxaline copolymer TQ1 (ESI, Fig. S7 $\dagger$ ). Plasmonic nanospectroscopy of a spin-coated $2: 1: 1 \mathrm{TQ} 1: \mathrm{C}_{60}: \mathrm{C}_{70}$ thin film reveals a $T_{\mathrm{g}} \sim 141{ }^{\circ} \mathrm{C}$, which is considerably higher than the glass transition temperatures of neat TQ1 (ref. 37: $T_{\mathrm{g}} \sim 100{ }^{\circ} \mathrm{C}$; ref. 30: $T_{\mathrm{g}} \sim 113{ }^{\circ} \mathrm{C}$ ), $1: 1 \mathrm{TQ} 1: \mathrm{PC}_{61} \mathrm{BM}$ (ref. 32: $T_{\mathrm{g}} \sim 120^{\circ} \mathrm{C}$ ), and $2: 1: 1$ TQ1 : $\mathrm{PC}_{61} \mathrm{BM}: \mathrm{PC}_{71} \mathrm{BM}$ (ref. 30: $T_{\mathrm{g}} \sim 120^{\circ} \mathrm{C}$ ). Similar to the ternary blend based on PTB7, we also find for TQ1 : $\mathrm{C}_{60}: \mathrm{C}_{70}$ that the $T_{\mathrm{g}}$ shifts to an even higher temperature for the second heating scan. Evidently, glassy bulk-heterojunctions with a high degree of thermal stability can also be achieved with other ternary blends of a donor plus a neat fullerene alloy.

\section{Conclusions}

We have established - using plasmonic nanospectroscopy - that a ternary blend of PTB7 and a $\mathrm{C}_{60}: \mathrm{C}_{70}$ fullerene alloy with a $2: 1: 1$ stoichiometry displays an exceptionally high glass transition temperature of $T_{\mathrm{g}} \sim 224{ }^{\circ} \mathrm{C}$, which is considerably higher than any other value reported to date for a donor: acceptor bulk-heterojunction. Electron microscopy confirmed the tendency of the ternary blend to form glassy, amorphous thin films with a homogeneous nanostructure. The photovoltaic performance of the corresponding solar cell active layers remained unaltered upon annealing at temperatures up to $T_{\text {anneal }} \sim 180{ }^{\circ} \mathrm{C}$, which was found to be in excellent agreement with the onset of the blend $T_{\mathrm{g}}$. Significant loss in photocurrent, but not photovoltage, coincided with the glass transition, giving rise to a continuous drop in power conversion efficiency for $T_{\text {anneal }}>180{ }^{\circ} \mathrm{C}$ from initially more than $5 \%$. We argue that true thermal stability of a photovoltaic blend can only be achieved if systems with a $T_{\mathrm{g}}$ significantly above the solar cell processing and operating temperatures are selected.

\section{Experimental section}

\section{Materials}

ortho-Dichlorobenzene (o-DCB, purity 99\%) was purchased from Sigma Aldrich. $\mathrm{C}_{60}$ and $\mathrm{C}_{70}$ with a purity of $99 \%$ were obtained from Solenne BV. Poly[(4,8-bis-(2-ethylhexyloxy)benzo(1,2- $\left.b: 4,5-b^{\prime}\right)$ dithiophene)-2,6-diyl-alt-(3-fluorothieno-(2ethylhexyl)-thieno(3,4-b)thiophene-4-carboxylate-2,6-diyl)] (PTB7) was purchased from Solarmer Materials, Inc. (number-average molecular weight $M_{\mathrm{n}} \sim 34 \mathrm{~kg} \mathrm{~mol}^{-1}$; polydispersity index PDI $\sim$ 2.4). Poly[2,3-bis-(3-octyloxyphenyl)quinoxaline-5,8-diyl-altthiophene-2,5-diyl] (TQ1) had a $M_{\mathrm{n}} \sim 71 \mathrm{~kg} \mathrm{~mol}^{-1}$ and PDI $\sim$ 3.7. The molecular weight was determined by size exclusion chromatography (SEC) with an Agilent PL-GPC 220 Integrated High Temperature GPC/SEC System in 1,2,4-trichlorobenzene at $150{ }^{\circ} \mathrm{C}$ using relative calibration against polystyrene standards.

\section{Plasmonic nanospectroscopy}

$T_{\mathrm{g}}$ measurements were carried out by plasmonic nanospectroscopy for which nanoplasmonic chips consisting of arrays of $\mathrm{Au}$ nanodisks of $170 \mathrm{~nm}$ and $20 \mathrm{~nm}$ of diameter and height, respectively, were employed. Details of the fabrication have been described elsewhere. ${ }^{\mathbf{2 9}, 30}$ The chips were mounted in an insulated quartz tube gas flow reactor system with optical access (Insplorion $\mathrm{X} 1$, Insplorion $\mathrm{AB}$, Göteborg, Sweden) connected to mass flow controllers (Bronkhorst) regulating the composition and total flow rate with a constant pressure of 1 atm. The chips were illuminated using a fibre-coupled halogen lamp (AvaLight-Hal-S, Avantes) while the wavelength-resolved extinction spectra (400$1100 \mathrm{~nm}$ ) were continuously recorded by using a fibre-coupled fixed grating spectrometer (AvaSpec-1024, Avantes). The working temperature (including the ramping rate) was set by the heating coil that is connected to the Eurotherm controller. The chip temperature was monitored via a thermocouple in direct contact with the surface of the chip. The sequence of $T_{\mathrm{g}}$ measurements in this work is as follows: (1) the chip was heated to $80{ }^{\circ} \mathrm{C}$ and dwelled for $1.5 \mathrm{~h}$ to remove any remaining solvents, (2) the temperature was reduced to $60{ }^{\circ} \mathrm{C}$, and (3) heating from 60 to $250{ }^{\circ} \mathrm{C}$ at a rate of $5{ }^{\circ} \mathrm{C} \mathrm{min}^{-1}$. All of the processes described were

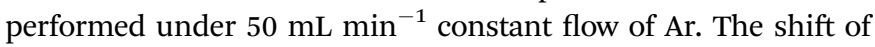
the LSPR peak $\Delta \lambda_{\text {peak }}$ was obtained by fitting the measured extinction spectra with a Lorentzian in the $\pm 100 \mathrm{~nm}$ wavelength range around the LSPR peak maximum.

\section{Thermal analysis}

Dynamic Scanning Calorimetry (DSC) was performed under nitrogen with a Mettler Toledo DSC 2 equipped with a Huber TC 125-MT intracooler at a scan rate of $20{ }^{\circ} \mathrm{C} \mathrm{min}^{-1}$. Thermal Gravimetric Analysis (TGA) was performed under nitrogen at a scan rate of $10{ }^{\circ} \mathrm{C} \mathrm{min}^{-1}$ with a Mettler Toledo TGA/DSC 3+. 


\section{Atomic force microscopy (AFM)}

AFM was performed in intermittent contact mode using an Agilent 5500 system in air.

\section{Transmission electron microscopy (TEM)}

Samples were prepared by spin-coating thin films on poly(3,4ethylene dioxythiophene) : poly(styrene sulfonate) PEDOT: PSS, followed by floating off films in water and finally collection with TEM copper mesh grids. TEM images were recorded with a $\mathrm{G}^{2} \mathrm{~T} 20$ Tecnai instrument operated at an acceleration voltage of $200 \mathrm{kV}$.

\section{Photoluminescence (PL) spectroscopy}

PL spectra of thin films were recorded using an Oriel liquid light guide and a Shamrock SR 303i spectrograph coupled to a Newton EMCCD silicon detector. The films were excited using a blue PMM-208G-VT laser pump $\left(4 \mathrm{~mW} \mathrm{~cm}^{-2}\right)$ with a wavelength of $532 \mathrm{~nm}$. PL data were scaled by sample absorption, and measured with a Perkin-Elmer Lambda 900 spectrophotometer equipped with an integrating sphere.

\section{Photovoltaic devices}

Photovoltaic devices were fabricated in standard device geometry, i.e. glass/ITO/PEDOT : PSS/active layer/LiF/Al ( $c f$. inset Fig. 4). ITO-patterned glass substrates were oxygen-plasma treated for $1 \mathrm{~min}$ prior to the deposition of the PEDOT : PSS electrode (Heraeus, Clevios P VP Al 4083, annealed at $120{ }^{\circ} \mathrm{C}$ for 15 min after spin-coating, thickness $\sim 40 \mathrm{~nm})$. PTB7 : fullerene active layers were prepared by (1) heating of fullerene solutions for two days at $27{ }^{\circ} \mathrm{C}$, (2) followed by addition of PTB7, (3) heating for about $2 \mathrm{~h}$ at $80{ }^{\circ} \mathrm{C}$, and then (4) spin-coating of the obtained $o$-DCB solutions, (5) followed by annealing of the active layer in a nitrogen-filled glovebox (before deposition of the top electrode) for 10 minutes at different temperatures (RT to $300{ }^{\circ} \mathrm{C}$ ). The thickness of the active layers was around $100-$ $110 \mathrm{~nm}$ as measured with a Dektak 150 surface profiler (estimated error $\pm 7 \mathrm{~nm}$ ). A LiF layer (thickness $\sim 6 \AA$ ) and aluminium top electrodes (thickness $\sim 90 \mathrm{~nm}$ ) were deposited via thermal evaporation under vacuum (below $4 \times 10^{-6} \mathrm{mbar}$ ). $J-V$ curves were recorded with a Keithley 2400 Source Meter under AM 1.5G illumination with an intensity of $100 \mathrm{~mW} \mathrm{~cm}^{-2}$ from a solar simulator (Model SS50A, Photo Emission Tech., Inc.). The light source used was a 180 watt xenon arc lamp solar simulator (Photo Emission Tech.). The intensity was calibrated using a standard silicon photodiode calibrated at the Energy Research Centre of the Netherlands (ECN). The active area of the solar cells was determined with an optical microscope.

\section{Electroluminescence (EL) spectroscopy}

EL spectra of solar cells were recorded using an Oriel liquid light guide and a Shamrock SR 303i spectrograph coupled to a Newton EMCCD silicon detector. Samples annealed at higher temperatures required a considerably larger positive bias for a comparable current density to be achieved: $0.84 \mathrm{~V}$ and $3 \mathrm{~V}$ for RT and 240-260 ${ }^{\circ} \mathrm{C}$ devices, respectively. EL spectra were collected at a current density of $21.7 \mathrm{~mA} \mathrm{~cm}^{-2}, 15.2 \mathrm{~mA} \mathrm{~cm}^{-2}$ and $10.9 \mathrm{~mA}$ $\mathrm{cm}^{-2}$ for RT, $240{ }^{\circ} \mathrm{C}$ and $260{ }^{\circ} \mathrm{C}$ devices, respectively.

\section{External quantum efficiency (EQE)}

EQE spectra of photovoltaic devices were recorded with a homebuilt setup using a Newport Merlin lock-in amplifier. Devices were illuminated with chopped monochromatic light through the transparent ITO electrode. Measured EQE spectra were scaled so that the estimated short-circuit current density from the EQE measurement matched the short-circuit current density of the corresponding $J-V$ curve.

\section{Acknowledgements}

Financial support from the Swedish Research Council, the Swedish Foundation for Strategic Research (grants RMA11-0037 and RMA15-0052) and the Swedish Energy Agency is gratefully acknowledged. We thank Dr Ergang Wang (Chalmers University of Technology) and Prof. Mats. Andersson (University of South Australia) for providing the TQ1 donor polymer used in this study, and Anders Mårtensson (Chalmers University of Technology) for expert help with atomic force microscopy.

\section{References}

1 J. Zhao, Y. Li, G. Yang, K. Jiang, H. Lin, H. Ade, W. Ma and H. Yan, Nature Energy, 2016, 1, 15027.

2 S. Hong, H. Kang, G. Kim, S. Lee, S. Kim, J.-H. Lee, J. Lee, M. Yi, J. Kim, H. Back, J.-R. Kim and K. Lee, Nat. Commun., 2016, 7, 10279.

3 M. Jørgensen, K. Norrman, S. A. Gevorgyan, T. Tromholt, B. Andreasen and F. C. Krebs, Adv. Mater., 2012, 24, 580.

4 F. C. Krebs, Sol. Energy Mater. Sol. Cells, 2009, 93, 2009.

5 Standard Test Methods for Photovoltaic Modules in Cyclic Temperature and Humidity Environments, ASTM Standard E 1171.

6 C. Müller, Chem. Mater., 2015, 27, 2740-2754.

7 X. Yang, J. K. J. van Duren, R. A. J. Janssen, M. A. J. Michels and J. Loos, Macromolecules, 2004, 37, 2151.

8 S. Bertho, I. Haeldermans, A. Swinnen, W. Moons, T. Martens, L. Lutsen, D. Vanderzande, J. Manca, A. Senes and A. Bonfiglio, Sol. Energy Mater. Sol. Cells, 2007, 91, 385.

9 S. Bertho, G. Janssen, T. J. Cleij, B. Conings, W. Moons, A. Gadisa, J. D'Haen, E. Goovaerts, L. Lutsen, J. Manca and D. Vanderzande, Sol. Energy Mater. Sol. Cells, 2008, 92, 753.

10 C. Müller, J. Bergqvist, K. Vandewal, K. Tvingstedt, A. S. Anselmo, R. Magnusson, M. I. Alsonso, E. Moons, H. Arwin, M. Campoy-Quiles and O. Inganäs, J. Mater. Chem., 2011, 21, 10676.

11 J. Bergqvist, C. Lindqvist, O. Bäcke, Z. Ma, Z. Tang, W. Tress, S. Gustafsson, E. Wang, E. Olsson, M. R. Andersson, O. Inganäs and C. Müller, J. Mater. Chem. A, 2014, 2, 6146.

12 J. Zhao, A. Swinnen, G. Van Assche, J. Manca, D. Vanderzande and B. Van Mele, J. Phys. Chem. B, 2009, 113, 1587. 
13 C. Bruner, F. Novoa, S. Dupont and R. Dauskardt, ACS Appl. Mater. Interfaces, 2014, 6, 21474.

14 D. Leman, M. A. Kelly, S. Ness, S. Engmann, A. Herzing, C. Snyder, H. Wook Ro, R. J. Kline, D. M. DeLongchamp and L. J. Richter, Macromolecules, 2015, 48, 383.

15 N. P. Holmes, M. Marks, P. Kumar, R. Kroon, M. G. Barr, N. Nicolaidis, K. Feron, A. Pivrikas, A. Fahy, A. Diaz de Zerio Mendaza, A. L. D. Kilkoyne, C. Müller, X. J. Zhou, M. R. Andersson, P. C. Dastoor and W. J. Belcher, Nano Energy, 2016, 19, 495.

16 C. Lindqvist, J. Bergqvist, C.-C. Feng, S. Gustafsson, O. Bäcke, N. D. Treat, C. Bounioux, P. Henriksson, R. Kroon, E. Wang, A. Sanz-Velasco, P. M. Kristiansen, N. Stingelin, E. Olsson, O. Inganäs, M. R. Andersson and C. Müller, Adv. Energy Mater., 2014, 4, 1301437.

17 J. J. Richards, A. H. Rice, R. D. Nelson, F. S. Kim, S. A. Jenekhe, C. K. Luscombe and D. C. Pozzo, Adv. Funct. Mater., 2013, 23, 514.

18 C. Lindqvist, J. Bergqvist, O. Bäcke, S. Gustafsson, E. Wang, E. Olsson, O. Inganäs, M. R. Andersson and C. Müller, Appl. Phys. Lett., 2014, 104, 153301.

19 B. C. Schroeder, Z. Li, M. A. Brady, G. C. Faria, R. S. Ashraf, C. J. Takacs, J. S. Cowart, D. T. Duong, K. H. Chiu, C.-H. Tan, J. T. Cabral, A. Salleo, M. L. Chabinyc, J. R. Durrant and I. McCulloch, Angew. Chem., Int. Ed., 2014, 53, 12870.

20 P. Cheng, C. Yan, Y. Wu, J. Wang, M. Qin, Q. An, J. Cao, L. Huo, F. Zhang, L. Ding, Y. Sun, W. Ma and X. Zhan, Adv. Mater., 2016, 28, 8021.

21 Z. George, Y. Xia, A. Sharma, C. Lindqvist, G. Andersson, O. Inganäs, E. Moons, C. Müller and M. R. Andersson, J. Mater. Chem. A, 2016, 4, 2663.

22 Y. Santo, I. Jeon, K. Sheng Yeo, T. Nakagawa and Y. Matsuo, Appl. Phys. Lett., 2013, 103, 073306.

23 S. Savagatrup, D. Rodriquez, A. D. Printz, A. B. Sieval, J. C. Hummelen and D. J. Lipomi, Chem. Mater., 2015, 27, 3902.
24 D. Angmo, M. Bjerring, N. C. Nielsen, B. C. Thompson and F. C. Krebs, J. Mater. Chem. C, 2015, 3, 5541.

25 A. Diaz de Zerio Mendaza, J. Bergqvist, O. Bäcke, C. Lindqvist, R. Kroon, F. Gao, M. R. Andersson, E. Olsson, O. Inganäs and C. Müller, J. Mater. Chem. A, 2014, 2, 14354.

26 A. Diaz de Zerio Mendaza, A. Melianas, S. Rossbauer, O. Bäcke, L. Nordstierna, P. Erhart, E. Olsson, T. D. Anthopoulos, O. Inganäs and C. Müller, Adv. Mater., 2015, 27, 7325.

27 A. Anctil, C. W. Babbitt, R. P. Raffaelle and B. J. Landi, Environ. Sci. Technol., 2011, 45, 2353.

28 C. Langhammer, E. M. Larsson, B. Kasemo and I. Zorić, Nano Lett., 2010, 10, 3529.

29 F. A. A. Nugroho, C. Xu, N. Hedin and C. Langhammer, Anal. Chem., 2015, 87, 10161.

30 F. A. A. Nugroho, A. Diaz de Zerio Mendaza, C. Lindqvist, T. J. Antosiewicz, C. Müller and C. Langhammer, Anal. Chem., 2017, DOI: 10.1021/acs.analchem.6b04807.

31 K. M. Mayer and J. H. Hafner, Chem. Rev., 2011, 111, 3828. 32 C. Lindqvist, A. Sanz-Velasco, E. G. Wang, O. Bäcke, S. Gustafsson, E. Olsson, M. R. Andersson and C. Müller, J. Mater. Chem. A, 2013, 1, 7174.

33 B. Watts, W. J. Belcher, L. Thomsen, H. Ade and P. C. Dastoor, Macromolecules, 2009, 42, 8392.

34 K. Tvingstedt, K. Vandewal, A. Gadisa, F. Zhang, J. Manca and O. Inganäs, J. Am. Chem. Soc., 2009, 131, 11819.

35 K. Vandewal, K. Tvingstedt, A. Gadisa, O. Inganäs and J. Manca, Nat. Mater., 2009, 8, 904.

36 K. Vandewal, K. Tvingstedt, A. Gadisa, O. Inganäs and J. Manca, Phys. Rev. B: Condens. Matter Mater. Phys., 2010, 81, 125204.

37 R. Kroon, R. Gehlhaar, T. T. Steckler, P. Henriksson, C. Müller, J. Bergqvist, A. Hadipour, P. Heremans and M. R. Andersson, Sol. Energy Mater. Sol. Cells, 2012, 105, 280. 